\title{
Quem tem direito ao "uso do véu"? (uma contribuição para pensar a questão brasileira)*
}

\author{
Céli Regina Jardim Pinto**
}

\begin{abstract}
Resumo
Este artigo analisa o dilema entre as posturas defensoras do universalismo e das diferenças, tendo como pressuposto que ambas podem resultar no reforço de essencialisarmos excludentes em cenários sociais de desigualdade. A hipótese que foi perseguida é a de que mesmo tomando como primado a necessidade da construção de uma "igualdade mínima essencial" isso só pode ocorrer tomando em consideração os princípios e as lutas que se organizam em torno do direito à diferença. Este paper tratará basicamente com a questão brasileira. A discussão que será levada a efeito aqui tem como base dois textos fundamentais: o relatório da comissão de alto nível que recomendou ao governo francês a proibição do uso véu pelas jovens mulçumanas nas escolas públicas francesas e o último livro de Seyla Benhabib The Claim of Culture.
\end{abstract}

Palavras-chave: Universalismo, Diferença, Mulheres, Religião, Esfera Pública.

\footnotetext{
* Recebido para publicação em abril de 2005, aprovado em outubro de 2005.

*** Professora da Universidade Federal do Rio Grande do Sul, Porto Alegre-RS. celirjp@terra.com.br
} 
Quem tem direito ao "uso do véu"?

Who Has the Right of Using the Scarf:

(a Contribution to Think the Brazilian Question)

\begin{abstract}
This article analyses the dilemma between the positions that has defended the universalism and those that has defended the differences, having as presupposition that both can result in the strong ness of exclude essentialism in scenario of social inequalities. The hypothesis that has pursued is as the follow: taking as presupposition the necessity of the construction of a "minimal essential equality" this only can take places taken into consideration the principle and the struggles that organize themselves around the right to the difference. This paper will discuss mainly the Brazilian question. The discussion that will be done in this paper has as bases two fundamentals texts: the Report of the High Commission that has recommended to the French government the prohibition of the use of the scarf by the young Muslim women in the French public school and the last book that was written by Seyla Benhabib - The Claim of Culture.
\end{abstract}

Key Words: Universalism, Difference, Women, Religion, Public Sphere. 
Céli Pinto

$\mathrm{O}$ presente artigo tem como questão central e articuladora as estratégias de inclusão de grupos marginalizadas cultural e/ou economicamente. Analisará o documento elaborado por um grupo de intelectuais franceses a pedido do Presidente da República sobre o uso do véu por jovens muçulmanas na escola, buscando elementos para discutir de forma mais abrangente políticas que incorporam o princípio da diferença, sejam elas de ação afirmativas ou não. Como subsídio para esta análise me valerei da importante reflexão sobre o assunto contida em recente livro de Seyla Benhabib. ${ }^{1}$

No que pese a centralidade da questão do uso do véu no debate feminista e a importância deste hábito na própria vida das mulheres muçulmanas ao redor do mundo, este artigo discute a estratégia de inclusão/exclusão de grupos e usando o caso francês como um exemplo paradigmático, não se propõe, portanto, a ser um estudo do caso em específico. ${ }^{2}$ Pretende, antes de tudo, ser uma reflexão, que contribua para a discussão sobre estratégias de inclusão no Brasil atual.

Em sociedades complexas, salvo indivíduos isolados por razão de enfermidade mental grave ou por extrema pobreza,

${ }_{1}$ BENHABIB, Seyla. The Claims of Culture - Equality and Diversity in the Global Era. Princeton, Princeton University Press, 2002.

2 A questão do islamismo $e$ os direitos das mulheres tem sido largamente debatida por teóricas feministas, por ONGs feministas e pelas próprias mulheres muçulmanas principalmente na Turquia e Irã. Sobre a questão do uso do véu são particularmente importantes os trabalhos de Nilufer Gole entre os quais destacam-se Musulmanes et modernes: voile et civilization em Turquie. Paris, Découverte, 1993 e The Forbidden Modern: Civilization and veiling. Ann Arbor, University of Michigan Press, 1996. Já no ano de 1992 duas antropólogas brasileiras discutiram a questão a propósito da primeira crise havida nas escolas francesas em 1989, onde retomam o tema fazendo um recorrido das atitudes tomadas pelo governo francês desde 1989 até os primeiro anos do novo século. ECKERT, Cornélia e RIAL, Carmen. O véu que divide a França. Revista Outra, vol. $1 \mathrm{n}^{\circ}$ 2, 1992. Em 2004, Seyla Benhabib lança The Rights of Others (Aliens, Residents and Citizens) Cambridge, Cambridge University Press, 2004. 
Quem tem direito ao "uso do véu"?

todos estão incluídos em alguma ordem. O fato, entretanto, de todos estarem incluídos não pressupõe que todos estejam incluídos da mesma forma e, muito menos, que todos estejam usufruindo dos mesmos direitos. Inclusão deve ser sempre entendida no plural, isto é, inclusões, o que leva a uma via de duas mãos: por um lado, é preciso ter presente que inclusões não pressupõem igualdade, justiça, participação, ou qualquer outra qualificação de ordem política, ética ou moral. Por outro lado, entretanto, a inclusão sempre pressupõe o reconhecimento da existência, mesmo que seja para reprimir; e, ainda, só os incluídos têm potencialmente a possibilidade de participar e lutar por igualdade de direitos. A inclusão também deve ser considerada em relação à díade público-privado: a inclusão em um certo tipo de ordem privada pode significar a exclusão na ordem pública. A questão da mulher é aqui particularmente exemplar, a sua inclusão na ordem familiar patriarcal, ao longo dos séculos determinou, em grande medida, sua quase total exclusão da ordem pública.

Inclusão, portanto, pressupõe reconhecimento das diferenças que não existem por natureza, mas se constituem historicamente, mudam de condição em contextos históricos distintos. Diferenças que não eram reconhecidas, nem autoatribuídas passam a ter existências concretas um determinado momento histórico. Talvez, o exemplo mais forte seja o da população gay. Há 50 anos atrás esta população simplesmente não existia como sujeitos passíveis de reconhecimento. A homossexualidade estava incluída em discursos morais-religiosos ou médicos, mas as pessoas homossexuais não buscavam reconhecimento, ao contrário, escondiam a condição, pois a única ordem possível de inclusão era no discurso do desvio.

Os trabalhos de Nancy Fraser são especialmente valiosos para avançar nesse tema. No seu aporte referente a questões de reconhecimento e redistribuição percebe-se uma clara trajetória. Em seus primeiros textos, reconhecimento e redistribuição apareciam como dois processos independentes atribuídos a 
sujeitos distintos, o reconhecimento era a forma de justiça que mais se adequava aos clamores dos gays, enquanto a redistribuição era vista como uma questão econômica que resolveria a questão das classes. Raça e gênero eram vistas por Fraser como bivalentes, necessitando redistribuição $e$ reconhecimento. ${ }^{3} \mathrm{Em}$ seu mais recente trabalho, sua posição é bastante diversa e oferece subsídios para o argumento que quero desenvolver neste artigo:

To build broad support for economic transformation requires challenging cultural attitudes that demand poor and working people, for example, "culture-of-poverty" ideologies that suggest they simply get what they deserve. Likewise, poor and working people may need a recognition politics to support their struggles for economic justice; they may need, that is, to build class communities and cultures in order to neutralize the hidden injuries of class and forge the confidence to stand up for themselves. Thus, a politics of class recognition may be needed both in itself and to help get a politics of redistribution off the ground. ${ }^{4}$

Esta segunda perspectiva tratada por Fraser tem importância especial no caso presente do Brasil, quando o governo começa a propor políticas de ação afirmativas, que envolvem políticas de reconhecimento. Estou referindo-me especificamente à atual (2005) discussão sobre políticas de cotas para estudantes negros e de egressos de escolas públicas nas universidades públicas do país. Até há muito pouco tempo a questão do ensino público dizia respeito à escola pública como instituição, à formação de professores, aos baixos salários destes mesmos professores, à falta de estrutura material de trabalho, à violência e à depredação dos

3 FRASER, Nancy. Justice Interrupus. Critical Reflections on the "postsocialist" condition. New York, Routledge, 1997, p.17.

4 Fraser, Nancy e HonNeth, Axel. Redistribution or recognition? A politicalphilosophical exchange. London, Verso, 2003, p.24. 
Quem tem direito ao "uso do véu"?

prédios Os alunos da escola pública eram vistos como conseqüência, eram positivamente incluídos quando se computava o número de crianças brasileiras em idade escolar que freqüentavam a escola. Eram negativamente incluídos como estatística de evasão e fracasso escolar.

Os alunos das escolas públicas brasileiras foram tratados até então como vítimas e não como sujeitos. Entretanto, no momento em que é proposta uma política compensatória que garante um percentual de vagas nas universidades públicas para alunos afrodescendentes e alunos de escolas públicas, está reconhecendo-se o direito de um grupo de pessoas, que completou o ensino médio em escolas oficiais do país.

$\mathrm{O}$ não reconhecimento (e por vias de consequência a exclusão) seria ignorar a existência deste aluno, através da construção de um tipo de retórica perversa, onde uma ou várias gerações são condenadas a não terem oportunidade no ensino superior, por conta da defesa de uma reforma no ensino médio, que resultará em efeitos positivos para gerações futuras.

Seyla Benhabib, em seu livro The Claims of Culture ${ }^{5}$, expõe um conjunto de teses que constituem uma contribuição muito importante para o avanço da discussão sobre políticas de reconhecimento. No que pese Benhabib estar particularmente preocupada com a questão da cultura e de populações multiculturais, seus argumentos permitem aprofundar a discussão sobre políticas de reconhecimento em situação de profunda desigualdade social.

A primeira questão central do livro é a que chama de "usos e abusos da Cultura". Benhabib aponta para uma reificação da cultura tanto por parte do pensamento conservador como do progressista. Essa tendência compartilha, segundo a autora, premissas epistemológicas imperfeitas, que entendem as culturas como fechadas, congruentes $e$, por conseguinte, não reconhecem a pluralidade cultural dentro dos grupos humanos, resultando em

${ }^{5}$ BENHABIB, S. The Claims of Culture... op.cit. 
uma sociologia da cultura reducionista, o que define a forma como se tem pensado a questão da injustiça sofrida por grupos na sociedade. Para a autora, que propõe um aporte de sociologia construtivista, a questão fundamental em reconhecer culturas distintas não é de preservá-las, mas de defendê-las em nome da justiça e da liberdade. ${ }^{6}$ Culturas não são reificações, mas:

Constant creations, recreations, and negotiations of imaginary boundaries between "we" and the "other(s)" The "other" is always also within us and is one of us. A self is a self only because it distinguishes itself from a real or more often than not imagined, "other".

A relação ente o "nós" e o "eles" é tensa e, segundo a autora, é muito difícil que o "nós" reconheça o direito de um "eles" profundamente diferente. Frente a isso propõe:

I argue that the task of democratic equality is to create impartial institutions in the public sphere and civil society where this struggle for the recognition of cultural differences and the contestation for cultural narratives can take place without domination. ${ }^{8}$

Benhabib introduz aqui um elemento fundamental no debate sobre igualdade, justiça, direitos diferenciados, que é a presença do Estado. Mesmo que não o cite explicitamente, fica bastante evidente a referência, quando menciona a criação de instituições. Essa referência é importante, pois nas discussões sobre reconhecimento de diferenças e direitos há uma tendência de identificar a ocorrência de espaços onde elas se manifestam na sociedade civil, que seria o espaço da diferença por natureza,

\footnotetext{
6 ID., IB., p.8.

7 ID., IB.

8 ID., IB.
} 
Quem tem direito ao "uso do véu"?

deixando o Estado como sendo uma reserva da igualdade para o cidadão da democracia liberal.

A noção da "igualdade democrática" enfatizada por Benhabib é especialmente importante, tomando em consideração o atual estado da arte da teoria da democracia e no nível prático da implantação de políticas compensatórias. O princípio da igualdade na discussão sobre a democracia foi de certa forma intimidada pela apropriação do tema pelo chamado socialismo real e sua derrocada na segunda metade do século $\mathrm{XX}$. A presença forte de filósofos liberais na discussão sobre justiça social tem também contribuído para deixar a discussão sobre igualdade distante da noção de democracia. Mesmo teóricos da democracia radical como Mouffe ${ }^{9}$ recolocam a noção como uma impossibilidade, porquanto em constante tensão como ao princípio da liberdade.

Para se recolocar a questão da igualdade na esfera da discussão sobre democracia, sem anular a centralidade do princípio de liberdade, uma possibilidade é a de se entender, ambas, igualdade e liberdade, como necessitando ser aprofundadas: uma radicalização da noção liberal de direitos, que viria a romper, em última instância, com a própria noção de igualdade liberal. Essa radicalização da noção liberal de direitos só pode se concretizar em um cenário, que se rompa com o universalismo liberal e sua cegueira intrínseca para as diferenças, isto não envolve, entretanto, abrir mão do universal como constituinte do princípio de igualdade e justiça. As perspectivas tanto do trabalho de Benhabib como o de Fraser, anteriormente citado, avançam nesta direção, na medida em que estão distantes de uma postura pós-moderna multiculturalista defensora da fragmentação, que tem sido muito associada às discussões sobre "diferença", direitos culturais, etc. Benhabib defende a idéia de uma universalismo interativo em contraposição ao um universalismo substitucionalista:

9 Mouffe, Chantal. Democratic Paradox. London, Verso, 2000. 
Substitionalist moral theories view individuals as generalized, not as concrete other... Interative universalism, by contrast, accepts that all moral being capable of sentience, speech, and action are potential moral conversation partners. ${ }^{10}$

Pensar o universal a partir da diversidade tem profundas implicações políticas e práticas, mormente, se a igualdade for tomada como um a priori na democracia. Pensar o outro como igual exatamente por suas diferenças, implica um realocamento de posições de poder com conseqüências profundas. Os argumentos contra as cotas para pessoas de etnias minoritárias no sistema educacional é um bom exemplo do que estou tratando de explicar. Uma elite branca não admite o sistema de cotas, partindo do princípio que as oportunidades são iguais para todos. $\mathrm{Na}$ medida em que só brancos entram no ensino superior, os negros passam a ser justificadamente discriminados como menos capazes. Ora se invertermos a equação e argumentarmos que as oportunidades não são iguais para todos, porque alguns partem de patamares historicamente colocados em níveis mais baixos, por pobreza e falta de oportunidade educacional, redefini-se a igualdade, deslocando-se a posição de poder da elite branca.

Indicar uma problemática como esta exige trazer para a discussão outras questões, e uma delas é central: ao admitir-se que grupos humanos podem se dividir quase que infinitamente, por atributos os mais variados e que tais divisões $e$ atribuições podem ter as mais diversas razões, nem todas libertárias e a favor dos próprios grupos, a questão que se impõe é a de como esses grupos chegam a condição de reivindicarem uma existência particular dotada de direitos. Benhabib propóe um modelo dinâmico de identidades de grupos, distinto dos multiculturalistas: "the multiculturalist is interested in classifying and naming groups and then in developing a normative theory on the basis of

${ }^{10}$ BenhaBIB, S. The Claims of Culture... Op.cit., p.14. 
Quem tem direito ao "uso do véu"?

classificatory taxonomies". ${ }^{11}$ A autora indica que uma estrutura pluralista para ser democrática e justa não pode violar três normas: reciprocidade igualitária; auto-definição voluntária; liberdade para sair ou associar-se.

Essas três normas dividem duas naturezas completamente distintas, a primeira, que garante igualdade de direito a todos os grupos é uma norma que deve ser assegurada pelo estado, as duas outras, mesmo que tenham algum amparo oficial, têm fundamentalmente a ver com a relação de cada indivíduo com o grupo, com o grau de liberdade que o indivíduo tem em relação ao grupo, com a pressão social $e$ as sansões que o indivíduo teria por tomar uma ou outra decisão. Em relação, por exemplo, à auto-definição, é bastante óbvio que um estado democrático não pode, em hipótese alguma, definir grupos, entretanto, isto não garante, e na verdade não há formas de garantir, que famílias, grupos de parentesco, grupos religiosos não induzam a definição das pessoas, assim como não controlem a possibilidade de entrada e saída. Tais obstáculos, não invalidam a importância das três normas, apenas chamam a atenção para as dificuldades que elas envolvem.

Um outro tema fundamental tratado por Benhabib, que envolve uma contribuição importante para a questão que estou tratando de examinar, está presente no capítulo três "From redistribution to Recognition? The paradigm Change of Contemporary Politics", no qual a autora faz severas críticas às posições de Taylor e Kimlicka a propósito do conceito de reconhecimento. Discute a tese de Taylor mostrando como ele divide com Honneth e Benjamin a idéia de reconhecimento como auto confiança $e$ auto respeito, isto é, como sendo um processo moral e psicológico. Tal posição, segundo Benhabib, leva Taylor a fazer uma identificação entre auto-identidade e identidade de grupo, o que para a autora pode resultar em um rompimento com

${ }^{11}$ ID., IB., p.18. 
o princípio de identificação individual, que deve ser entendido em uma outra perspectiva.

It is both theoretically wrong and politically dangerous to conflate individual's search for the expression of his-her unique identity with politics of identity/difference. The theoretical mistake comes from the homology drawn between individual and collective claims. ${ }^{12}$

A questão examinada por Benhabib permite focalizar com muita propriedade algumas dificuldades postas na prática por esse tipo de equívoco. Em casos limites, de ditadura, fanatismo religioso, ou grande ameaça externa a uma cultura ou mais amplamente a uma forma de vida, essa identificação pode se verificar, mas se pensarmos em cotidianos sem níveis de tensão radicais, o indivíduo tem uma teia complexa de fatores que the dão consistência como individualidade, enquanto uma certa cultura pode de maneira mais ou menos aleatória constituir-se de forma harmônica e unitária.

Benhabib aponta outro sério problema de políticas que enfatizam as diferenças culturais, ao analisar a questão do multiculturalismo e a cidadania de gênero. Para Benhabib as formas de convivência multiculturais levam em grande medida a reforçar as condições de dominação das mulheres, pois as culturas tendem a ser patriarcais. $\mathrm{O}$ argumento cultural segundo a autora transforma indivíduos (agentes morais) em fantoches de suas culturas. A defesa, por exemplo, de um indivíduo que cometeu um crime a partir de sua extração cultural leva a considerar o indivíduo como apenas uma conseqüencia de sua cultura. Benhabib se pergunta por que outros indivíduos da mesma cultura frente ao mesmo problema não cometem crimes.

The cultural defense strategy imprisons the individual in a cage of univocal cultural interpretations and psychological

12 ID., IB., p.53. 
Quem tem direito ao "uso do véu"?

motivations; individual's intentions are reduced to cultural stereotypes; moral agency is reduced to cultural puppetry. ${ }^{13}$

Se a consideração da cultura no julgamento pode fazer justiça ao criminoso, não faz justiça a vítima. Isto é particularmente forte quando a questão refere-se a relações entre homens $e$ mulheres, onde assassinatos, torturas, privação de liberdade, são justificados como princípios culturais. Até onde, pergunta a autora, mulheres que estão em contato com diferentes culturas e com a própria luta feminista, principalmente mulheres migrantes em países europeus ou nos Estados Unidos desejam manter estes princípios culturais. ${ }^{14}$

$\mathrm{O}$ aporte de Benhabib à questão da presença de culturas múltiplas introduz elementos importantes na discussão, que tanto entre os teóricos como na prática dos grupos e dos estados tendem a ser reduzidas aos argumentos de contra ou a favor. A análise do caso do uso do véu por jovens francesas em escolas públicas é paradigmática de um aporte que toma em consideração as contradições e as potencialidades do encontro entre culturas e a esfera pública. Benhabib argumenta que, se por um lado, o uso do véu indica uma submissão das mulheres, por outro, lhes possibilita entrar em contato com uma cultura laica e com outras culturas o que trará mais possibilidade de colocar em xeque suas condições, o que não aconteceria se fossem afastadas do convívio público e condenadas a frequentar escolas religiosas ou simplesmente permanecerem na clausura doméstica. Discutindo o caso de três jovens, que ficou famoso pela repercussão ainda em 1989, Benhabib afirma:

Ironically, they used the freedom given to them by French society and French political traditions, not the least of which is the availability of free and compulsory public education for all children on French soil, to juxtapose an aspect of

\footnotetext{
${ }^{13}$ ID., IB., p. 89.
}

${ }^{14}$ ID., IB., p.93. 
their private identity into the public sphere. In doing so, they problematized the school as well as the home: they no longer treated the school as the neutral space of French acculturation, but openly manifested their cultural and religious differences, They used the symbolic of the home in the public sphere, retaining the modesty required of them by Islam in covering their heads; yet at the same time, they left the home to become public actors in a civil public space, in which they defied the state. ${ }^{15}$

A análise do relatório que se segue tem especial relevância dentro do objetivo que perseguimos, por um conjunto de razões, entre elas: por se tratar de um documento escrito por intelectuais franceses a pedido da presidência da república e que resultou em posterior lei; por ter sido filosoficamente justificado a partir dos princípios de uma democracia estável que se auto-referencia em uma postura republicana; por tratar de um grupo diferenciado que é representativo de um fenômeno de surgimento de novas identidades, quer seja consequência da grande vaga migratória ocorrida no século XX dos povos pobres em direção ao hemisfério norte; quer seja conseqüência da grande efervescência dos movimentos sociais, que apareceram no mundo ocidental (mas não só) principalmente a partir da década de 70 do século passado; finalmente por se referir a mulheres jovens em um país onde o feminismo teve uma de suas mais importantes manifestações.

A diferença como a promotora da desigualdade é uma questão de difícil resolução e que deve ser cuidadosamente refletida, para que não dê guarida a posturas chauvinistas: a diferença não é promotora de igualdade ou desigualdade em si, isto é, não é garantindo à cultura que se atingirá, em princípio a igualdade, da mesma forma isto não acontece automaticamente proibindo manifestações que apontam para a reprodução da desigualdade. Decorre disto que o direito à diferença cultural deve

${ }^{15}$ ID., IB., p. 97. 
Quem tem direito ao "uso do véu"?

ser pensado de forma distinta de acordo com os cenários. O direito a diferença tende a ser entendido como próprio do cenário da sociedade civil, enquanto o direito a igualdade na diferença é próprio da luta política do cenário da esfera pública oficial. Isto, no entanto, não torna a questão mais fácil e leva ao segundo ponto do argumento de Benhabib, que é a negação da essencialização da cultura, tema que percorre todo o seu livro. A forma como a autora coloca a questão é particularmente importante como background para a discussão atual sobre políticas de ação afirmativa tipo cotas e outras, tanto na arena dos movimentos sociais, como na arena do Estado. Como a discussão, mesmo nos meios acadêmicos, toma uma forma de partido (no sentido de lado), as posições tendem a se radicalizar contra ou a favor, na maioria das vezes a partir de argumentos essencialistas. Permito-me, pois, citar um longo trecho, antes de passar para a análise do documento:

I believe that there are no such holistic structures of consciousness and that advocates of social positionality themselves operate with the fiction of a unitary consciousness in that they reduce the contentious debates of every human group about itself and its identity to a coherent and easily delineable narrative. Ironically, cultural essentialism comes back to haunt its most vocal critics, because those who argue that human cultures are human creations also argue that individuals are imprisoned in the perspectival refractions of their social positions. Both claims - cultural essentialism as well as social perspectivism - are false. ${ }^{16}$

II

Na segunda parte deste artigo o propósito central é colocar em discussão o relatório ao Presidente da República Francês

${ }^{16}$ ID., IB., p.137. 
redigido pela Comissão de Reflexão sobre a aplicação do princípio de laicidade na república datado de 11 de dezembro $2003^{17}$, que se constituiu na verdade em um documento sobre o direito das jovens mulçumanas usarem véus nas escolas públicas francesas. A hipótese que norteará esta análise é a de que o relatório constrói um argumento que inviabiliza qualquer experiência no território francês de pluralismo identitário e de alargamento democrático pela incorporação de diferenças.

O relatório, que está dividido em quatro partes, é introduzido por uma carta ao Presidente da República, onde a comissão estabelece as bases a partir das quais elaborou o documento, que se refere a ameaça aos valores da república francesa por grupos extremistas. Esses grupos segundo o relatório, devido ao conflito no Oriente Médio estariam criando problemas nas cidades francesas. "C'est tenant compte de ces menaces et à lumière des valeurs de notre Republique, que nous avons formule les propositions qui figurent dans ce rapport." 18

Há, portanto, um território ameaçado a partir de dentro pelo estranho, por aquele que não faz parte do "nous", em contraposição a uma unidade formada pelos valores franceses. A primeira parte do relatório trata da laicidade, como princípio universal e valor republicano. A laicidade é entendida como uma conquista frente a influência da Igreja Católica, garantindo a plena liberdade de culto e a neutralidade do estado. Entretanto, essa não é a questão central do argumento, mas sim a ameaça aos valores franceses nunca definidos pela presença de manifestações religiosas. O relatório textualmente afirma:

La défense de la liberté de conscience individuelle contre tout prosélytisme vient aujourd'hui compléter les notions de

\footnotetext{
${ }^{17} \mathrm{O}$ relatório - "Rapport au President de la Republique. Commission de Reflexion sur l'application du principe de laícite dans la Republique", 11 de dezembro de 2003 - encontra-se no site www.ladocfrancaise.gouv.fr, acessado em 10 de janeiro de 2004 .

${ }^{18}$ ID., IB., p.7.
} 
Quem tem direito ao "uso do véu"?

séparation et de neutralité centrales dans la loi de 1905 [e completa mais adiante] l'école ne saurait devenir la chambre d'écho des passions du monde, sous peine de faillir à sa mission éducative. ${ }^{19}$

A França, como de resto toda a Europa ocidental e o Reino Unido, tem sido cenário nas últimas décadas de uma grande efervescência de culturas imigrantes, além de identidades constituídas a partir dos novos movimentos sociais como o feminista, movimentos de defesa de opções sexuais, etc. Ora estes sujeitos se encontram nas mais diversas esferas públicas no país, interagem, hibridizam-se e, ao mesmo tempo, buscam novos adeptos ou apoiadores. A formação de uma consciência individual ocorre, entre outras coisas, pelo enfrentamento com diferenças, quanto maior for a inserção pública dos indivíduos de culturas, religiões $e$ identidades diversas, maior as possibilidades de escolhas. Não se pode confundir a neutralidade do estado e de seus representantes legais (servidores públicos) com a neutralidade do cidadão. Possivelmente o espaço público mais aberto para o entendimento e/ou confronto de idéias e posições é a escola, que, ao contrário do que prediz o relatório, tem sido "eco das paixões do mundo", até pelo elemento de juventude que contém.

A Europa em geral e a França em particular enfrentam a diluição de uma cultura pretensamente unívoca calcada em valores vividos como universais. Estes valores, como será possível perceber ao longo do argumento do relatório, são tomados como pétreos, não admitindo contestação. $\mathrm{Na}$ verdade são resignificados de forma cada vez mais excludente, na medida em que são "ameaçados" no confronto com novas culturas, por exemplo, é interessante observar que o conceito de laicidade é construído como um referente único dos "valores comuns da sociedade" 20 , onde o islamismo aparece a priori como

\footnotetext{
${ }^{19}$ ID., IB., p.14.

${ }^{20}$ ID., IB., p.15.
} 
incompatível, na medida em que pressupõe uma relação diferente entre o estado e a religião. Uma pergunta impõe-se, o que é o islamismo que existe na França? Há um islamismo ou muitos islamismos? Todos os praticantes da religião relacionam-se com os não praticantes da mesma forma? Como o islamismo é modificado/ou não quando exercido em um país majoritariamente cristão? O relatório impõe à "cultura do outro" uma unidade que dificilmente existe, uma vez que os imigrantes além de muçulmanos têm nacionalidades distintas, chegaram em momentos distintos e ocupam posições diversas na sociedade. Benhabib mostrou bastante claramente o equívoco de confundir a experiência dos indivíduos com idéias unívocas e equivocadas de cultura.

O que fica bastante claro no relatório é que o islamismo não poderá ser uma diferença (uma cultura) constitutiva de um espaço público plural, mas só será tolerada, quando for praticado no espaço privado. A diferença neste caso vem de encontro a um princípio que inclusive dá título a uma das partes do relatório: "viver junto, construir um destino comum". Nesta parte, o relatório enfatiza a diversidade de novas religióes e culturas que vivem na França e que dão a ela a "Chance de s'enrichir du libre dialogue entre ces diverses composantes". Mas logo em seguida define a filosofia política francesa como a expressão da defesa da unidade do corpo social e o que é mais caracterizador do "espírito do relatório" "Ce souci d'uniformité l'emportait sur toute expression de la différence perçue comme menaçante". O relatório revela uma visão reducionista da questão de reivindicação dos direitos culturais, quando atribui sua reivindicação a necessidades de auto-afirmação e não a uma luta por justiça social. Neste sentido o relatório aproxima-se da perspectiva de Honneth ${ }^{21}$, mas diferentemente do pensador

${ }^{21}$ HonNeTH, Axel. Luta por Reconhecimento - a gramática moral dos conflitos sociais. São Paulo, Editora 34, 2003. 
Quem tem direito ao "uso do véu"?

alemão, nega a legitimidade da identidade devido a sua autoreferência.

A afirmação do universalismo dos ideais franceses é introdutória para que se afirme que as diferenças levadas ao fanatismo são portadoras da opressão $e$ da exclusão. ${ }^{22}$ Não há dúvida sobre isso e a maioria dos teóricos que discutem o tema concordaria com a afirmação, entretanto, a idéia de unidade de valores universais pode resultar exatamente no mesmo tipo de exclusão, na medida em que trata o "outro" como anomia, pode ser visto pelo "outro" como um sistema fechado, como um fundamentalismo: a percepção da unidade e da diferença como ameaça resulta na mesma situação de exclusão.

A segunda parte do relatório ("A Laicidade francesa, um princípio jurídico aplicado com empirismo") discute o ponto de tensão entre a neutralidade do Estado laico versus a liberdade religiosa. É especialmente interessante observar que aparece como solução a possibilidade de criação de escolas mulçumanas. $\mathrm{O}$ problema, no entanto, não está na existência destas escolas, pois igualmente pode haver escolas católicas, protestantes, israelitas, etc. A questão complica-se quando a escola religiosa confina os praticantes de uma religião, deixando de ser uma opção para ser a única possibilidade de educação. A exigência da não manifestação da religião na escola pública parece confundir a laicidade do estado com uma pressuposta "laicidade do cidadão".

Tomando como referência o que se examinou na primeira parte deste artigo, a questão não está na defesa essencialista de culturas ou religióes, mas na possibilidade delas interagirem. $\mathrm{O}$ argumento, algumas vezes presente no relatório, confunde estas duas percepções: quando aponta que certas religiões têm ritos que vêm de encontro aos princípios básicos de higiene em hospitais, isto não pode servir de justificativa para proibir o uso de véus em aulas. Da mesma forma pode-se argumentar que se um aluno interrompe uma aula e se põe a rezar em voz alta, por

${ }^{22}$ Rapport au President... Op. cit., p.17. 
determinação religiosa, está havendo o rompimento de um pacto de convivência. O que de forma alguma é o caso do uso de roupas ou símbolos religiosos, pois não perturba ou impedem direitos coletivos. Um padre ou uma freira da Igreja Católica, que por determinação de sua ordem fosse obrigado a usar batina ou hábito, não poderia freqüentar uma escola pública francesa? Para sair de exemplos religiosos: um aluno de uma escola pública deveria ser proibido de usar roupas que o identificasse com grupos de skin head, punks, etc., mesmo que seu rendimento escolar e comportamento social não fossem diferentes dos outros alunos? Ou sobre isto o Estado não deve se manifestar, porque não tem nada a ver com a laicidade.

O relatório faz um recorrido da questão da laicidade e do multiculturalismo na Europa contemporânea e chega a um exemplo bastante ilustrativo para a discussão que estamos querendo levar a efeito, o caso da Holanda. O relatório aponta para um cenário de tribalização neste país decorrente de uma política multicultural. "Les élèves originaires de l'immigration se retrouvent dans les mêmes établissements qualifiés 'd'écoles noires'." Também a terceira geração de filhos de imigrantes voltam-se para o islamismo, diferente de seus pais. Frente a isto, segundo o relatório francês, o governo holandês abriu mão de políticas multiculturais em favor de políticas de integração ao "valeurs fondatrices de la société néerlandaise". ${ }^{23}$

Estamos frente a uma versão reducionista e essencialista de multicluturalismo, muito distinta da esfera plural e multicultural proposta por Benhabib. O multiculturalismo holandês, descrito no relatório, leva ao isolamento e a tendência ao reforço de um "purismo" cultural. Benhabib é bastante enfática sobre os limites do multiculturalismo radical, que trata culturas como puras, porém também indica os limites de um republicanismo cívico, que criando critérios rígidos de assimilação provoca exatamente os efeitos que combate. É interessante notar que o renascimento

${ }^{23}$ ID., IB., p.35. 
Quem tem direito ao "uso do véu"?

do islamismo entre jovens, até em suas versões mais radicais, ocorre tanto na Holanda como na França, que possuem políticas absolutamente distintas, mas que provocam o mesmo isolacionismo e radicalização da cultura/religião. O que ocorre é que em ambas as situações o Estado não possibilitou a integração através da incorporação da cultura do outro como mais uma cultura capaz de modificar e ser modificada. O isolamento, somado a questões sempre presente de preconceitos e da própria crise de empregos, tende a levar os jovens a buscar identificação em um passado reconstruído idealmente.

$\mathrm{Na}$ terceira parte do relatório sob o título de "O desafio da Laicidade" é trabalhada com muito detalhe a questão central que suscitou o relatório, o uso do véu por jovens muçulmanas. $\mathrm{O}$ relatório aponta a volta do uso do véu como uma regressão na situação das mulheres nas comunidades muçulmanas, que estariam sendo obrigadas a usá-los sob pena de serem estigmatizadas com prostitutas. O relatório afirma textualmente:

Les jeunes filles, une fois voilées, peuvent traverser les cages d'escalier d'immeubles collectifs et aller sur la voie publique sans craindre être conspuées, voire maltraitées, comme elles l'etaient auparavant, tête nue. Le voile leur offre ainsi, paradoxalement, la protection que devrait garantir la République. Celles qui ne portent pas et le perçoivent comme un signe d'infériorisation qui enferme et isole les femmes sont désignées comme "impudique", voire "infidèles". ${ }^{24}$

Aparece aqui um conjunto muito importante de situações a examinar a partir deste pequeno texto. Partamos de uma presunção, que o relatório está errado e que as jovens usam o véu por livre espontânea vontade, até porque sentem-se despidas sem ele, devido a cultura da qual fazem parte. Eu, particularmente, concordo com o relatório que o véu é prova da discriminação e da

${ }^{24}$ ID., IB., p.47. 
posição subalterna da mulher na religião muçulmana, pelo menos na forma que chegou até o mundo contemporâneo. Entretanto, a pergunta que necessita ser respondida é: em que contribuiria para mudar a posição da mulher a proibição do véu? Não levaria, de forma distinta a uma tendência a afirmação da diferença e uma radicalização e justificação da cultura sexista?

De forma diversa, se partirmos da presunção que o relatório está certo, que as jovens são obrigadas a usar o véu, a questão permanece a mesma: qual a justiça que se faria a estas mulheres ao obrigá-las a não usar o véu? Com poderia o estado francês garantir uma vida digna a estas mulheres se elas rompessem com a sua comunidade? Teria o Estado como garantir a "boa vida" a estas mulheres apartadas de suas famílias e de sua comunidade?

Se estas mulheres, ou porque não querem ou porque não têm liberdade, passam a não freqüentar a escola porque não lhe é permitido não usar o véu, qual é o serviço que o estado francês está fazendo a favor da liberação destas mulheres?

Concordo plenamente com Benhabib que a única forma de agir com justiça com estas mulheres é permitir que elas sejam expostas ao espaço público, laico, diferenciado. Que elas estejam em locais públicos, e a escola laica francesa é um desses locais privilegiados, onde possam expressar-se e ouvir posições distintas das suas. Aí reside a possibilidade da retirada do véu a seu favor. Possivelmente, neste cenário, muitas mulheres retirariam o véu, outras tantas não. Mas esta é a única forma igualitária de tratar todos os cidadãos.

O relatório associa ao uso do véu uma série de outras práticas como não assistirem aulas de educação física, não usarem piscinas públicas, não permitirem serem examinadas por médicos do sexo masculino. Fora da escola, o sexismo da religião muçulmana é apontado no local de trabalho, onde os homens não aceitam terem superiores mulheres, ou como já foi citado o ato de pacientes e familiares não obedecerem princípios básicos de higiene em hospitais. Estes exemplos são de qualidade muito distintas e confundem questões que podem ser vistas como de 
Quem tem direito ao "uso do véu"?

fórum privado com questões que dizem respeito ao interesse coletivo, ou ao tratamento igualitário dos cidadãos. O fato das mulheres não freqüentarem as piscinas públicas porque há homens é uma questão privada, outras mulheres não muçulmanas também podem não se sentir a vontade em uma piscina, ou mesmo não a frequentarem por não as acharem higiênicas. A piscina pública não pode criar impedimentos para que qualquer pessoa a frequente, neste particular cabe a comunidade construir piscinas com horários diferentes se assim entenderem. Quanto a ser examinado por médicos ou médicas, esse deveria ser um direito de todas as pessoas e principalmente das mulheres, na medida em que são cada vez mais freqüentes as denúncias por parte de pacientes de abusos sexuais em consultórios médicos, principalmente de mulheres jovens. ${ }^{25}$

Os outros exemplos têm qualidades diferentes, que envolvem o bem estar e direitos coletivos. O caso do hospital é o mais grave, porque diz respeito à saúde e à vida das pessoas $e$ cabe ao estado garanti-las. No caso das aulas de educação física, não se pode submeter pessoas a vestirem-se com roupas que as fazem sentir despudoradamente nuas. ${ }^{26}$ Por outro lado, essas jovens só poderão ser introduzidas às atividades físicas se estas lhe forem proporcionadas dentro dos limites de sua própria identidade como pessoas. Finalmente, o caso dos homens que não aceitam chefes mulheres, também é só através da exposição que esta situação poderá ser superada. Lembremos que a menos de meio século atrás isto também não era aceito por homens ocidentais europeus.

A última parte do relatório intitulada "afirmar uma laicidade firme que reúna" é especialmente importante, pois é nela que o relatório propõe medidas para garantir a laicidade, que tomam

\footnotetext{
${ }^{25}$ Não se está afirmando que tenha crescido o número de casos de abusos sexuais por parte de médicos homens, o que ocorre é o maior número de denúncias, por força de uma nova posição da mulher na sociedade.

${ }^{26}$ Lembremo-nos que a nudez tem sido uma forma de tortura aos prisioneiros Afegãos por parte das forças militares norte americanas
} 
um caráter muito mais abrangente do que a simples garantia de neutralidade religiosa do estado: parece aqui quase como uma ideologia do estado para garantir os valores da "cultura francesa" e a integração de todos que moram no país a ela.

$\mathrm{O}$ relatório recomenda a formação universitária de professores para ensinar a filosofia da laicidade e os valores da república e para ensinar fatos religiosos e a deontologia laica. Também sugere um serviço civil para os jovens que deverá favorecer "le bressage social". ${ }^{27} \mathrm{Em}$ um esforço claro de apagar diferenças recomendam o fim do programa que permitia o ensino da língua e cultura dos países de origem. A manifestação da comissão é bastante esclarecedora:

Cet enseignement relève d'une logique communautariste. Il est assuré par des enseignants étrangers, rémunères par le pays d'origine pour des jeunes, que, eux, sont souvent de nationalité française et vont vocation à vivre en France définitivement. $^{28}$

Quanto à escola é bastante interessante o argumento do relatório, que identifica de um lado a família como o espaço de dominação da mulher imigrante (victimes de pressions exercées dans le cadre familial ou dans le quartier), por outro lado, identifica o espaço escolar que deve ser para as jovens "un lieu de liberté et d'émancipation". Porque a escola deve ser este espaço, o relatório justifica a proibição do uso nas escolas de indumentária ou outros sinais que revelem pertencimento a alguma religião ou organização política.

O relatório em seu conjunto apresenta uma sólida posição contra a aceitação de qualquer manifestação cultural que não se enquadre na chamada cultura francesa laica. Toda a expressão de cultura imigrante (na verdade árabe) é vista como uma anomalia. Os imigrantes não podem manter suas línguas maternas e seus

${ }^{27}$ ID., IB., p.52.

${ }^{28}$ ID., IB., p.53. 
Quem tem direito ao "uso do véu"?

costumes devem ser desafiados na escola. Às mulheres, principalmente às jovens adolescentes, cabe o papel quase heróico de desafiar a família, a comunidade para encontrar a liberdade na escola francesa. Ao contrário do que foi discutido na primeira parte deste artigo, no relatório, a cultura é tomada como não permeável e a cultura do outro só é entendida como ameaça. O temor do proselitismo entre os jovens não muçulmanos de idéias religiosas é muito revelador do aspecto de embate que o relatório toma em relação ao que é considerado não francês. Talvez o momento mais radical do relatório seja a justificativa para que não se ensine mais a língua do país de origem dos imigrantes para seus filhos, pois eles são franceses. A morte da cultura através do esquecimento provocado parece ter sido a solução encontrada pela comissão.

IIIPara introduzir a terceira e conclusiva parte deste artigo gostaria de evocar o direito ao uso do véu, isto é, o direto à diferença no espaço público, não como a reafirmação do véu e dos símbolos que o envolve, mas exatamente pela possibilidade que o véu dá para as mulheres muçulmanas na França de saírem do espaço restrito da casa, de entrarem em contato com posturas distintas, filosofias, modos de vida. Que estas jovens seriam diferentes dentro de uma aula, não resta dúvida, mas não tratá- las como tal, resulta em duas situações: mantê-las fora da escola ou em escolas religiosas, em ambas as circunstâncias seriam reforçadas a guetização, a dominação, a pobreza, a obediência, o silêncio. O véu é certamente a marca da dominação, mas também é a marca da expressão de uma diferença, que não deixa de existir só porque é proibida de ser expressa.

A proibição do uso do véu confina as diferenças ao espaço privado, reforçando a tendência à essencialização de culturas. $\mathrm{O}$ relatório repete ao longo de seu detalhado argumento a falácia identificada por Benhabib de confundir o indivíduo com a cultura/demandas culturais. Não reconhece na jovem que usa o véu uma pessoa, que exposta a outras culturas, que aceita 
no espaço público, pode se transformar e ser um agente transformador na volta ao espaço privado. O relatório assume o que Benhabib chama de incomensurabilidade das culturas, tanto da cultura francesa, como da cultura muçulmana. Neste particular é que a incomensurabilidade tem um sinal positivo quando é a cultura francesa e negativo quando se refere à cultura do outro.

Benhabib indica muito fortemente a necessidade da presença do estado na promoção de instituições imparciais na esfera pública, no entanto, isso não pressupõe o não reconhecimento das diferenças. O relatório francês está muito centralizado na responsabilidade estatal em promover essas instituições, mas ao contrário do argumento de Bernhabib, exige imparcialidade dos sujeitos que entram em contato com ele.

No obstante os conteúdos contidos tanto no trabalho teórico de Benhabib como no relatório da Comissão estarem muito distante da problemática brasileira, os temas levantados são subsídios importantes para tratar as questões da democracia brasileira, que estão na pauta no momento, a saber, políticas compensatórias: quem tem direito no Brasil, através da reafirmação de suas diferenças, de lutar por igualdade na esfera pública. Quem tem direto a usar "véu" no Brasil?

Tomando como base o que foi discutido neste artigo, a resposta mais abrangente a esta questão é a seguinte: tem direito a usar véus todos os cidadãos e cidadãs que por questões culturais, de raça, etnia, classe, sexo, religião, opção sexual, idade não têm condições de usufruir em sua totalidade o direito a terem direitos. Em um país como o Brasil onde as desigualdades sociais atingem proporções de catástrofe, onde as populações negras e indígenas estão entre as mais pobres e excluídas de direitos, meu argumento é que essas populações devem chegar a esfera pública através da reafirmação de suas identidades, não com objetivo de reafirmá-la como essencial, ou manter tradições, mas porque a afirmação da identidade é uma forma de fazer justiça e de incluir essas populações. Se as jovens muçulmanas francesas proibidas de usar o véu podem ficar excluídas das escolas públicas, os jovens 
Quem tem direito ao "uso do véu"?

brasileiros pobres, negros, trabalhadores se não trouxerem para a esfera pública estas marcas, que, historicamente, tem sido a razão da exclusão (exatamente pelo não reconhecimento da diferença), também continuarão fora do direito ao ensino formal público em todos os níveis. Isso no caso do Brasil não se restringe à questão da educação, mas envolve uma gama diferenciada de populações que, por etnia, cultura, graus de pobreza e até local de moradia, têm sido excluídas historicamente do direito a ter direitos. Quando a reprodução dessas desigualdades é vivida como natural, até pelos que sofrem com elas, a reafirmação das diferenças como forma de inclusão e superação da miséria, da falta de educação formal e de tantos outros direitos é fundamental.

O espaço da educação, especialmente a escola, por suas características intrínsecas é fundamental para criar um novo caldo de cultura que rompa isolamentos e proporcione uma interação mais igualitária entre as pessoas. É a partir dessa perspectiva que o tema do direito ao uso ao véu traz uma potencialidade muito grande para se pensar a questão brasileira. Se nossa cultura popular é uma mescla muito profícua de influências, onde negros $e$ índios comparecem com muita vivacidade, nossa cultura erudita, aquela que possibilita ascensão social, trabalho, realização profissional, condições de educação, saúde e moradia dignas é uma cultura homogênea, branca, de classe média, que deixa vastas parcelas excluídas. Os dados relativos à educação desde o ensino fundamental até o ensino superior mostram com muita força a exclusão das camadas pobres e dentre elas da população negra e, nesse sentido, o efeito é paradoxalmente, para os incluído e excluídos, o mesmo. Esclareço: a desigualdade como princípio de assujeitamento atua igualmente para criar diferentes graus de cidadania, onde os que se identificam como portadores de direitos não vêem os não portadores como cidadãos dotados destes direitos e estes últimos, eles próprios, não se identificam como também portadores de direito. Em comunidades complexas, como é o caso da francesa e da brasileira, mudar posições relativas na sociedade depende de um conjunto de ações determinadas 


\section{Céli Pinto}

combinadas com tempo, que podem resultar em diferentes cenários. Entretanto, o que parece fundamental é romper a cultura dominante, não através do assujeitamento dos que estão fora dela, pois isso tem revelado resultados socialmente irrelevantes, na medida em que esses grupos não reconhecidos em suas especificidades entram no campo escolar, por exemplo, em uma posição de falsa igualdade. $\mathrm{O}$ caso francês não é de ação afirmativa como tende a ser o caso brasileiro, mas em ambas as situações o reconhecimento da diferença parece ser fundamental para criar condições positivas de integração dos grupos em questão em um pacto cidadão que garanta igualdades de direitos. 